\title{
AVALIAÇÃO DA DOR LOMBAR CRÔNICA EM PRATICANTES AMADORES DE MUSCULAÇÃO PONDERADOS PELOS INSTRUMENTOS: Oswestry e Roland Morris
}

\section{Lucas Amaro Salsa Ferreira ${ }^{1}$ \\ Danillo Barbosa ${ }^{2}$}

Resumo: A dor lombar acomete uma parcela importante da população mundial, e é uma das principais causas de lesões em indivíduos praticantes de atividades físicas em especial a musculação, Trata-se de um estudo controlado, randomizado, duplo cego, qualiquantitativo, descritivo e analítico. Os instrumentos de avaliação que foram utilizados nesse estudo são: Oswestry e Roland Morris (RMDQ), A escolha dos participantes foi feita de forma aleatória. A amostra foi composta por 50 indivíduos, sendo 25 do gênero masculino e 25 do gênero feminino. Os resultados da análise dos instrumentos para o gênero feminino apontou um valor de $P<0,0003$, já para o grupo do gênero masculino observou-se um valor de $P<0,0415$ foi considerado relevante, confirmando a dor lombar entre os mesmos. Conclui-se que a amostra analisada no presente estudo apresenta dor e incapacidade lombar na prática constante da musculação.

Palavras-chave: Musculação; Dor lombar; Fisioterapia; Lombalgia.

\footnotetext{
${ }^{1}$ Fisioterapia/FEPI-Centro Universitário de Itajubá, Brasil. E-mail: lucasamaro19@hotmail.com.

2 Fisioterapia/FEPI-Centro Universitário de Itajubá, Brasil. E-mail: danillo.barbosa@hotmail.com.
} 